\title{
Laser interstitial thermal therapy followed by minimal-access transsulcal resection for the treatment of large and difficult to access brain tumors
}

\author{
James Wright, MD, ${ }^{1}$ Jessey Chugh, MD, ${ }^{1}$ Christina Huang Wright, MD, ${ }^{1}$ Fernando Alonso, MD, ${ }^{1}$ \\ Alia Hdeib, MD, ${ }^{1,2}$ Haley Gittleman, MS, ${ }^{3}$ Jill Barnholtz-Sloan, PhD, ${ }^{3}$ and Andrew E. Sloan, MD ${ }^{1-3}$ \\ ${ }^{1}$ Department of Neurological Surgery, University Hospitals Case Medical Center; ${ }^{2}$ Case Western Reserve University School of \\ Medicine; and ${ }^{3}$ Case Comprehensive Cancer Center, Cleveland, Ohio
}

\begin{abstract}
OBJECTIVE Laser interstitial thermal therapy (LITT), sometimes referred to as "stereotactic laser ablation," has demonstrated utility in a subset of high-risk surgical patients with difficult to access (DTA) intracranial neoplasms. However, the treatment of tumors larger than $10 \mathrm{~cm}^{3}$ is associated with suboptimal outcomes and morbidity. This may limit the utility of LITT in dealing with precisely those large or deep tumors that are most difficult to treat with conventional approaches. Recently, several groups have reported on minimally invasive transsulcal approaches utilizing tubular retracting systems. However, these approaches have been primarily used for intraventricular or paraventricular lesions, and subtotal resections have been reported for intraparenchymal lesions. Here, the authors describe a combined approach of LITT followed by minimally invasive transsulcal resection for large and DTA tumors.
\end{abstract}

METHODS The authors retrospectively reviewed the results of LITT immediately followed by minimally invasive, transsulcal, transportal resection in 10 consecutive patients with unilateral, DTA malignant tumors $>10 \mathrm{~cm}^{3}$. The patients, 5 males and 5 females, had a median age of 65 years. Eight patients had glioblastoma multiforme (GBM), 1 had a previously treated GBM with radiation necrosis, and 1 had a melanoma brain metastasis. The median tumor volume treated was $38.0 \mathrm{~cm}^{3}$.

RESULTS The median tumor volume treated to the yellow thermal dose threshold (TDT) line was $83 \%$ (range $76 \%$ $92 \%$ ), the median tumor volume treated to the blue TDT line was $73 \%$ (range $60 \%-87 \%$ ), and the median extent of resection was $93 \%$ (range $84 \%-100 \%$ ). Two patients suffered mild postoperative neurological deficits, one transiently. Four patients have died since this analysis and 6 remain alive. Median progression-free survival was 280 days, and median overall survival was 482 days.

CONCLUSIONS Laser interstitial thermal therapy followed by minimally invasive transsulcal resection, reported here for the first time, is a novel option for patients with large, DTA, malignant brain neoplasms. There were no unexpected neurological complications in this series, and operative characteristics improved as surgeon experience increased. Further studies are needed to elucidate any differences in survival or quality of life metrics.

http://thejns.org/doi/abs/10.3171/2016.8.FOCUS16233

KEY WORDS glioma; stereotactic laser ablation; LITT; NeuroBlate; tumor; metastatic; craniotomy

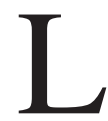

ASER interstitial thermal therapy (LITT), also termed "stereotactic laser ablation," has proven to be effective as a minimally invasive treatment for difficult to access (DTA) tumors and has thus effectively expanded the range of treatable intracranial tumors by enabling effective ablation of tumors once widely considered inoperable. ${ }^{6,13,14,30,33-36}$ However, many of the neoplasms treated with LITT in the recent literature have been small $(\leq 10$ $\mathrm{cm}^{3}$, which corresponds to a sphere of radius $1.33 \mathrm{~cm}$ ). Smaller lesions are easier to treat to the appropriate thermal dose threshold (TDT), and one recent large study ${ }^{27}$ demonstrated that $12(92 \%)$ of 13 tumors in the "favorable" prognostic group were $\leq 10 \mathrm{~cm}^{3}$, whereas only $5(23 \%)$ of 22 tumors in the "unfavorable" prognostic group were $\leq$

ABBREVIATIONS CUSA = cavitron ultrasonic surgical aspirator; DTA = difficult to access; $\mathrm{GBM}=$ glioblastoma multiforme; iMRI = intraoperative MRI; LITT = laser interstitial thermal therapy; OS = overall survival; PFS = progression-free survival; TDT = thermal dose threshold; WBRT = whole-brain radiation therapy.

SUBMITTED June 1, 2016. ACCEPTED August 1, 2016.

INCLUDE WHEN CITING DOI: 10.3171/2016.8.FOCUS16233. 
$10 \mathrm{~cm}^{3}$. All of the tumors in the favorable group were $<11$ $\mathrm{cm}^{3}$. Moreover, complications after LITT for large tumors have been documented or described by experienced LITT surgeons. ${ }^{13,15}$ These complications are usually caused not by immediate postoperative injury, but by the swelling that commonly occurs after LITT, which leads to local mass effect or elevated intracranial pressure requiring urgent craniectomy, debulking, or both. ${ }^{6,13,15,28}$ Thus, several groups have warned that LITT is best suited for tumors with diameters $\leq 3 \mathrm{~cm}$, which corresponds to a tumor volume of approximately $14.1 \mathrm{~cm}^{3}$. Because many thalamic and callosal "butterfly" tumors at our tertiary care referral center are larger than the $10-14-\mathrm{cm}^{3}$ threshold, this size restriction limits which tumors can be treated with the conventional application of this promising technology.

Recently, several groups have described minimally invasive transsulcal approaches using tubular retractor systems to access deep tumors. , $3,3,8,25,37$ However, in demonstrations at both training centers and our own institution, many of these approaches appear to yield subtotal resection, which is less extensive than the resection typically required to optimize survival in patients with malignant tumors. ${ }^{7,20}$

After performing LITT for a large tumor early in our experience, malignant edema occurred, necessitating emergent craniotomy and resection of the tumor because of increased swelling and mass effect. At the time, we noted that the tumor, a recurrent glioblastoma multiforme (GBM), was surprisingly soft and avascular with the consistency of currant jelly. We have not routinely adopted the use of tubular transsulcal retractor systems for tumors we consider "resectable" via more conventional approaches. We were also skeptical of the outcomes of conventional resection of DTA tumors-particularly those in the thalamus or corpus callosum - even while using the surgical adjuncts described in previous reports. ${ }^{7,20}$ However, given our experience with LITT in appearing to change tumor consistency by making it less vascular and more "suckable," combined with our intention of fully treating the tumor using LITT, we hypothesized that elective tumor resection using this minimally invasive transportal technique via a small craniotomy and tubular retractor immediately after LITT would enable safe resection of DTA malignant tumors larger than $10 \mathrm{~cm}^{3}$. Since LITT was the primary method of treatment for the tumor, our goal was not to achieve extensive resection, but rather to debulk the tumor to accommodate the expected swelling observed after LITT and thus avoid herniation or the need for emergent decompression. Herein, we report the results of 10 consecutive cases treated between 2014 and 2016 in which we combined LITT with a minimally invasive "keyhole" or "transportal" approach to large and DTA tumors using 1-2 unilateral trajectories. Using this approach, we avoided the need for emergent decompressive surgery in response to swelling in our series of 10 consecutive patients. To our knowledge, no studies have examined the potential of such a minimally invasive surgery combined with LITT.

\section{Methods}

\section{Patient Demographics}

After receiving institutional review board approval, we performed a retrospective chart review of patients who had undergone LITT followed by a minimally invasive surgical approach. We identified 10 patients, 5 males and 5 females, each harboring a single lesion treated in one procedure performed by a single surgeon at University Hospitals in Cleveland, Ohio, between February 2014 and May 2016. The demographics, tumor volume, clinical history, and indications for surgery are listed in Table 1. Tumor volume was calculated based on MRI measurements and the assumption that the tumors were ellipsoid. The median age among the 10 patients was 65 years. Eight patients had GBMs (2 recurrent and 6 newly diagnosed; all IDH-1 and ATRX wild-type), 1 had radiation necrosis in the field of a previously diagnosed GBM, and 1 had melanoma brain metastasis refractory to previous whole-brain radiation therapy (WBRT), radiosurgery, and chemotherapy. Two patients had "butterfly" gliomas of the corpus callosum, and 1 had a thalamic tumor. Seven patients had undergone biopsy or other diagnostic or therapeutic intervention, whereas 3 did not. The median tumor volume was 38.0 $\mathrm{cm}^{3}$ (range $10.6-77.7 \mathrm{~cm}^{3}$ ).

\section{Surgical Technique}

Laser interstitial thermal therapy was performed as previously described using the NeuroBlate platform (Monteris Medical). ${ }^{36}$ In brief, all patients underwent preoperative MRI with contrast-enhanced T1-weighted volumetric sequences (isotropic 1-mm voxels, magnetizationprepared rapid gradient echo [MPRAGE]). These images were transferred to iPlan version 2.3 (Brainlab AG), and the probe trajectory and skull entry point were planned. We aimed to select a trajectory along the center of the long axis of the lesion to optimize the NeuroBlate treatment. Simulation with the Surgical Theatre platform (Surgical Theatre, Inc.) was also used to optimize trajectory in 6 cases. In some cases, diffusion tensor imaging fiber tractography was also used during planning to identify nearby critical white matter tracts.

All patients were intubated and placed under general anesthesia and in an MR-compatible 3- or 4-point head-fixation device. A separate trajectory guide, attached percutaneously to the skull, was used to mount the laser. For the first 5 cases the AXiiis device was used. ${ }^{21}$ A newly developed cranial bolt (Monteris Medical) was used for the last 5 cases. In either situation, the cranial fixation device was mounted based on the desired stereotactic trajectory, which was based on preoperative MRI. After the cranial fixation device was secured, patients who had not undergone recent biopsy underwent a biopsy using stereotactic guidance. A histological diagnosis was provided by a board-certified, fellowship-trained tumor neuropathologist.

After the cranial fixation device had been applied and the biopsy performed (when required), the patient's head was wrapped in a sterile, translucent plastic cranial drape and a flexible cranial coil was secured around the head. The patient was then transferred to the 3-T intraoperative MRI (iMRI) unit in the adjacent room. After securing the patient in the iMRI unit, the cranial region was again prepared and draped and the remote probe driver was fixed to the trajectory guide. The laser was set to a length that corresponded to just outside the tumor margin and was then 
TABLE 1. Summary of characteristics in 10 patients with DTA lesions treated using LITT combined with minimally invasive surgery

\begin{tabular}{|c|c|c|c|c|c|c|c|}
\hline $\begin{array}{l}\text { Case } \\
\text { No. }\end{array}$ & $\begin{array}{l}\text { Age } \\
\text { (yrs) }\end{array}$ & Sex & Tumor Location & Tumor Type & $\begin{array}{l}\text { Lesion } \\
\text { Vol }\left(\mathrm{cm}^{3}\right)\end{array}$ & Previous Treatment & Indication for Surgery \\
\hline 1 & 52 & M & Rt thalamus & GBM & 77.7 & Subtotal resection & Residual large tumor \\
\hline 2 & 56 & $\mathrm{~F}$ & $\begin{array}{l}\text { Anterior corpus callo- } \\
\text { sum (butterfly GBM) }\end{array}$ & GBM & 39.2 & None & Large butterfly GBM \\
\hline 3 & 70 & M & $\begin{array}{l}\text { Corpus callosum (but- } \\
\text { terfly glioma) }\end{array}$ & GBM & 69.6 & Biopsy & Large butterfly GBM in an elderly patient \\
\hline 4 & 51 & M & Lt frontal & rGBM & 13.2 & $\begin{array}{l}\text { Resection It occipitopari- } \\
\text { etal GBM, RC*; biopsy } \\
\text { of new It frontal lesion } \\
\text { (original lesion stable) }\end{array}$ & Distant recurrence of GBM \\
\hline 5 & 63 & M & Lt parietal & $\begin{array}{l}\text { Metastatic } \\
\text { melanoma }\end{array}$ & 14.2 & $\begin{array}{l}\text { WBRT, GKRS, chemo } \\
\text { (tumor progressed) }\end{array}$ & $\begin{array}{l}\text { Large radiation-resistant neoplasm recurring } \\
\text { post-SRS }\end{array}$ \\
\hline 6 & 75 & $\mathrm{~F}$ & Rt frontoparietal & GBM & 22.5 & Biopsy & $\begin{array}{l}\text { Very aged patient w/ multiple comorbidities \& } \\
\text { large tumor }\end{array}$ \\
\hline 7 & 53 & M & Rt frontotemporal & GBM & 63.9 & Resection, RC & Large rGBM after treatment failure \\
\hline 8 & 82 & $\mathrm{~F}$ & Rt frontal & GBM & 50.2 & None & $\begin{array}{l}\text { Very elderly patient w/ large tumor w/ mass } \\
\text { effect, weakness, brain compression }\end{array}$ \\
\hline 9 & 67 & $\mathrm{~F}$ & Rt frontal & $\begin{array}{l}\text { Radiation } \\
\text { necrosis }\end{array}$ & 19.0 & $\begin{array}{l}\text { Malignant glioma after } \\
\text { SRS, now w/ RN }\end{array}$ & $\begin{array}{l}\text { Elderly patient after multiple craniotomies, RT, } \\
\text { w/ both rGBM \& RN }\end{array}$ \\
\hline 10 & 84 & $\mathrm{~F}$ & Lt frontal & GBM & 10.6 & None & $\begin{array}{l}\text { Very elderly patient w/ large tumor w/ mass } \\
\text { effect in dominant regions; eloquent region, } \\
\text { fMRI not useful, poor candidate for mapping }\end{array}$ \\
\hline
\end{tabular}

Chemo = chemotherapy; $f M R I$ = functional MRI; GKRS = Gamma Knife radiosurgery; RC = radiochemotherapy; rGBM = recurrent GBM; RN = radiation necrosis; RT = radiotherapy; SRS = stereotactic radiosurgery.

* Stupp et al., 2005.

inserted in a sterile fashion. A 3.3-mm diffusing tip laser probe was used in all 10 cases.

Pretreatment MR images included FLAIR, T2 diffusion-weighted, and T1-weighted volume spoiled gradientrecalled acquisition in the steady state. The T1-weighted spin echo images that included an image volume containing the probe trajectory were acquired for NeuroBlate treatment target planning. Using the NeuroBlate software and the T1-weighted images, the surgeon manually segmented the tumor. The surgeon also identified temperature reference points outside the tumor but within $2 \mathrm{~cm}$ of the tumor margin. The trajectory set on the trajectory guide in the operating room was verified. The laser probe was then advanced to the target by using the robotic probe driver, which is controlled by the surgeon from the MRI control room. ${ }^{13,15,28,36}$ During treatment, real-time thermometry data were displayed by the software in 3 consecutive images ( $5 \mathrm{~mm}$ thick and $0.25-\mathrm{mm}$ gap) in a plane perpendicular to the probe. Thermal deposition is typically first observed in the treatment "slice"- the plane containing the location of the laser exit. The lowest thermal dose demarcation appears first and begins to enlarge with continued lasing. In each case, the surgeon's goal was to optimize delivery of the thermal energy at the blue TDT to the tumor volume while minimizing the dose at the yellow TDT to surrounding nonneoplastic tissue. The deposition of thermal energy outside the tumor into cisterns, ventricles, sulci, and subarachnoid space was permitted at the discretion of the surgeon. Depending on the size and geometry of the tumor, applications of laser energy at multiple angles and depths were required using 1-2 trajectories. Laser treatment was initiated by the surgeon and stopped manually when the predicted thermal ablation zone was sufficient and stopped automatically if any monitored limits were exceeded. Typically, laser treatment occurred in an iterative process within a treatment plane until the thermal dose volume conformed to the tumor boundary. As additional laser applications were performed, previously calculated thermal doses were added to subsequent overlapping laser applications. The probe was either advanced or retracted to treat other planes within the tumor until maximum coverage of the prescribed thermal injury was achieved.

At the conclusion of thermal ablation, the patients, each of whom had tumors larger than $10 \mathrm{~cm}^{3}$ in volume, were returned to the operating suite to undergo craniotomy for resection of the targeted treatment area with the goal of removing residual tumor and reducing the effect of periprocedural edema due to thermal coagulation. After removing the plastic cranial drape, the field was irrigated with $500 \mathrm{ml}$ of bacitracin irrigation solution, the trajectory guide (AXiiis or bolt) was removed, and the small incision was closed. After the first case resulted in an infection, a separate sterile prep and draping was performed after LITT but before the craniotomy for all subsequent cases. A small incision $(5-10 \mathrm{~cm})$ was made and craniotomy was performed in the standard fashion. The goal of the craniotomy was not to achieve imaging-complete resection, as in a case treated with conventional surgery, but rather to debulk the treated tissue to avoid postoperative swelling and mass effect, which was believed to be potentially 


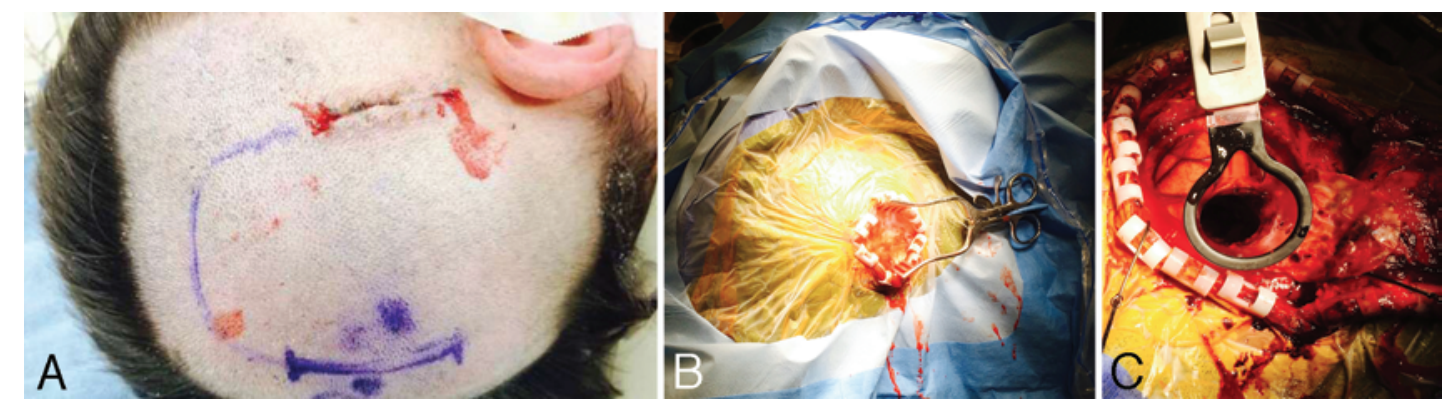

FIG. 1. Illustration of the transsulcal technique utilizing a tubular retractor system. A: A previous biopsy site is located just above the ear. For this early case, a conventional flap was drawn on the scalp in case the minimally invasive approach was inadequate. Fortunately, only the original incision was required. B: The wound previously used for biopsy is reopened. C: After a small craniotomy, dural opening, and sulcal dissection, a tubular retractor is placed into the sulcus and directed toward the tumor, which is then resected through the tube using a Sonopet device and bipolar cautery as per the surgeon's preference.

life threatening in these cases given previous reports on and experience with large tumors with an expected course of increased swelling for at least 48 hours. ${ }^{13,15,26-28,33,36}$ The first case in this series was resected using a conventional malleable retractor attached to the Layla bar. In the 9 remaining patients, the ViewSite Brain Access System (VBAS; Vycor Medical Inc.) was used.

In all cases, an appropriate sulcus was identified and the tubular system was aligned in the appropriate trajectory under stereotactic guidance (Fig. 1). Using microscopic magnification and stereotactic guidance, we removed tumor with a cavitron ultrasonic surgical aspirator (CUSA) or Sonopet device, which was tracked stereotactically. In all cases, the tumor had the consistency of currant jelly and was avascular. The surgeon was able to easily resect adequate tumor and achieve hemostasis within 20-40 minutes of dural opening. Hemostasis was achieved with irrigation and the judicious use of hemostatic agents. The closure was performed in a standard fashion, and a sterile dressing was applied.

\section{Postoperative Care}

All patients were monitored in the neurological intensive care or step-down unit in the immediate postoperative period before transfer to the regular nursing floor. All patients were placed on high-dose dexamethasone therapy, $10 \mathrm{mg}$ intravenously every 6 hours for a period of 72 hours. All patients were also placed on $25 \mathrm{mg}$ of intravenous mannitol every 6 hours for 24 hours. Following the initial 72-hour period, all patients were weaned to $2 \mathrm{mg}$ of oral dexamethasone twice daily over a period of 7-10 days. Postoperative MRI was performed in all patients on postoperative Day 1-2. All patients were evaluated by physical and occupational therapy, as well as nutrition and speech therapy when indicated.

\section{Results}

\section{Extent of LITT and Extent of Resection}

The outcomes for all cases are provided in Table 2. The median tumor volume treated to the yellow TDT (representing $43^{\circ} \mathrm{C}$ for 2 minutes) was $83 \%$ (range $76 \%-92 \%$ ), and the median tumor volume treated to the blue TDT (representing $43^{\circ} \mathrm{C}$ for approximately 10 minutes) was
$73 \%$ (range $60 \%-87 \%$ ). The median extent of resection of enhancing tumor was $92 \%$ (range $84 \%-100 \%$ ). Two representative cases are illustrated in Figs. 2 and 3. All patients went on to receive additional therapies as indicated.

\section{Complications}

Two patients suffered mild neurological deficits, which were transient in 1 case. Three patients had medical complications including an infection of the surgical wound, a local pin site infection from the cranial fixation, and hydrocephalus. There were no deaths, and 6 patients had no complications. Four patients had died from their tumors at the time of this analysis, and 6 patients remain alive.

\section{Survival Analysis}

Kaplan-Meier survival curves were generated along with their corresponding 95\% confidence intervals for progression-free survival (PFS) and overall survival (OS). Median survival times with corresponding 95\% confidence intervals were calculated as well. All analyses were performed using $\mathrm{R}$ version 3.1.2. For both PFS and OS, there were 4 events among 10 patients. The median PFS was 280 days (95\% CI 482 days-not calculable [NC]; Fig. 4 left), and the median OS was 482 days (95\% CI 121 days-NC; Fig. 4 right).

\section{Discussion}

This series comprises 10 patients who were thought to have a poor prognosis based on their demographics, histological diagnosis, tumor size, and tumor location. They were believed to be poor candidates for treatment with conventional surgical approaches, and their tumors were believed too large to treat safely and effectively with LITT without the significant risk of potentially life-threatening postoperative swelling. The median patient age was 65 years. Age is a known prognostic factor for both GBMs and brain metastases, and our patients were older than those in most other previous series. ${ }^{4,5,11,27,28,36}$ From a histological standpoint, patients with unresectable recurrent GBM typically have a median survival of about 5 months even after radiochemotherapy.,20,39 Though 1 patient in our study had recurrent melanoma brain metastasis, the prognosis for this disease is similarly poor., ${ }^{5,11}$ 
TABLE 2. Outcomes in 10 patients with DTA lesions treated using LITT combined with minimally invasive surgery

\begin{tabular}{|c|c|c|c|c|c|c|c|c|c|}
\hline $\begin{array}{l}\text { Case } \\
\text { No. }\end{array}$ & $\begin{array}{c}\text { Tumor } \\
\text { Treated } \\
\text { to Yellow } \\
\text { TDT }\end{array}$ & $\begin{array}{l}\text { Tumor } \\
\text { Treated } \\
\text { to Blue } \\
\text { TDT }\end{array}$ & $\begin{array}{l}\text { Extent of } \\
\text { Resection }\end{array}$ & $\begin{array}{l}\text { Neurological } \\
\text { Deficits }\end{array}$ & $\begin{array}{c}\text { Other } \\
\text { Complications }\end{array}$ & $\begin{array}{l}\text { Subsequent } \\
\text { Treatment }\end{array}$ & $\begin{array}{l}\text { Vital } \\
\text { Status }\end{array}$ & $\begin{array}{c}\text { FU } \\
\text { (days) }\end{array}$ & $\begin{array}{l}\text { PFS } \\
\text { (days) }\end{array}$ \\
\hline 1 & $76 \%$ & $60 \%$ & $84 \%$ & $\begin{array}{l}\text { Transient mild focal It } \\
\text { shoulder weakness }\end{array}$ & Wound infection, seizure & RT \& chemo & Alive & 176 & 176 \\
\hline 2 & $83 \%$ & $74 \%$ & $92 \%$ & None & None & RT \& chemo & Deceased & 254 & 121 \\
\hline 3 & $81 \%$ & $71 \%$ & $86 \%$ & None & None & RT \& chemo & Deceased & 111 & 88 \\
\hline 4 & $82 \%$ & $81 \%$ & $96 \%$ & None & $\begin{array}{l}\text { Pin site infection (unre- } \\
\text { lated to surgical wound) }\end{array}$ & RT \& chemo & Deceased & 280 & 94 \\
\hline 5 & $92 \%$ & $87 \%$ & $96 \%$ & $\begin{array}{l}\text { Mild increased imbal- } \\
\text { ance }\end{array}$ & None & $\begin{array}{l}\text { Immunotherapy w/ } \\
\text { checkpoint inhibitor }\end{array}$ & Alive & 366 & 366 \\
\hline 6 & $88 \%$ & $79 \%$ & $93 \%$ & None & None & RT \& chemo & Alive & 46 & 46 \\
\hline 7 & $79 \%$ & $67 \%$ & $85 \%$ & None & None & DCVax vaccine; Avastin & Deceased & 501 & 482 \\
\hline 8 & $77 \%$ & $61 \%$ & $87 \%$ & None & Hydrocephalus & RT \& chemo & Alive & 121 & 120 \\
\hline 9 & $84 \%$ & $73 \%$ & $97 \%$ & None & None & RT \& chemo & Alive & 108 & 108 \\
\hline 10 & $86 \%$ & $77 \%$ & $100 \%$ & None & None & RT \& chemo & Alive & 98 & 98 \\
\hline
\end{tabular}

FU = follow-up.

Our patients had large, DTA, malignant intracranial tumors that were treated with LITT followed by minimalaccess transportal resection. Six (60\%) of our patients had lesions that would be considered unresectable or highly morbid in other series, including 3 patients with tumors in eloquent cortex (dominant left frontal and parietal lobes), 2 patients with butterfly GBMs, and 1 patient with a thalamic lesion. ${ }^{28,33}$ Typically, butterfly GBMs are biopsied but not resected. ${ }^{1}$ Similarly, thalamic GBMs in adults are generally considered unresectable, with previous series demonstrating morbidity of $14 \%-30 \%$ and mortality of $6 \% .{ }^{19,32}$ Radiosurgery has not proven effective. ${ }^{38}$

A recent review ${ }^{26}$ of 21 peer-reviewed studies of LITT for tumor revealed that only 3 of the studies included patients with a tumor volume $>10 \mathrm{~cm}^{3}$. In a study of DTA gliomas, only $29 \%$ of the patients had tumors of the thalamus, corpus callosum, and insula. ${ }^{27}$ Although that multicenter study included patients with tumors up to $50 \mathrm{~cm}^{3}$ in size, the authors found that TDT lines were closely associated with prognosis. Although tumor size alone did not appear to be statistically significant, $12(92 \%)$ of 13 patients in the favorable prognostic group had a tumor volume of $10 \mathrm{~cm}^{3}$ or less and all had a tumor volume of 11 $\mathrm{cm}^{3}$ or less. Another study of LITT for thalamic tumors had a complication rate of $67 \%$, and one of the complications was fatal. ${ }^{33}$ All of our patients had tumor volumes $>10 \mathrm{~cm}^{3}$ and $9(90 \%)$ had volumes $>11 \mathrm{~cm}^{3}$, suggesting that they would probably be in the unfavorable prognostic group of earlier studies. ${ }^{13,27,33}$ One experienced group of authors has noted high complication rates $(100 \%)$ in patients with tumor volumes $>20 \mathrm{~cm}^{3}$ that were treated with LITT, and another group documented post-LITT swelling in patients with tumors $\geq 3 \mathrm{~cm}$ in diameter, or approximately $14.1 \mathrm{~cm}^{3}$ in volume, and has cautioned against using LITT in such large-volume cases. . $^{13,15,16}$

Despite the poor prognosis of patients in our study, as
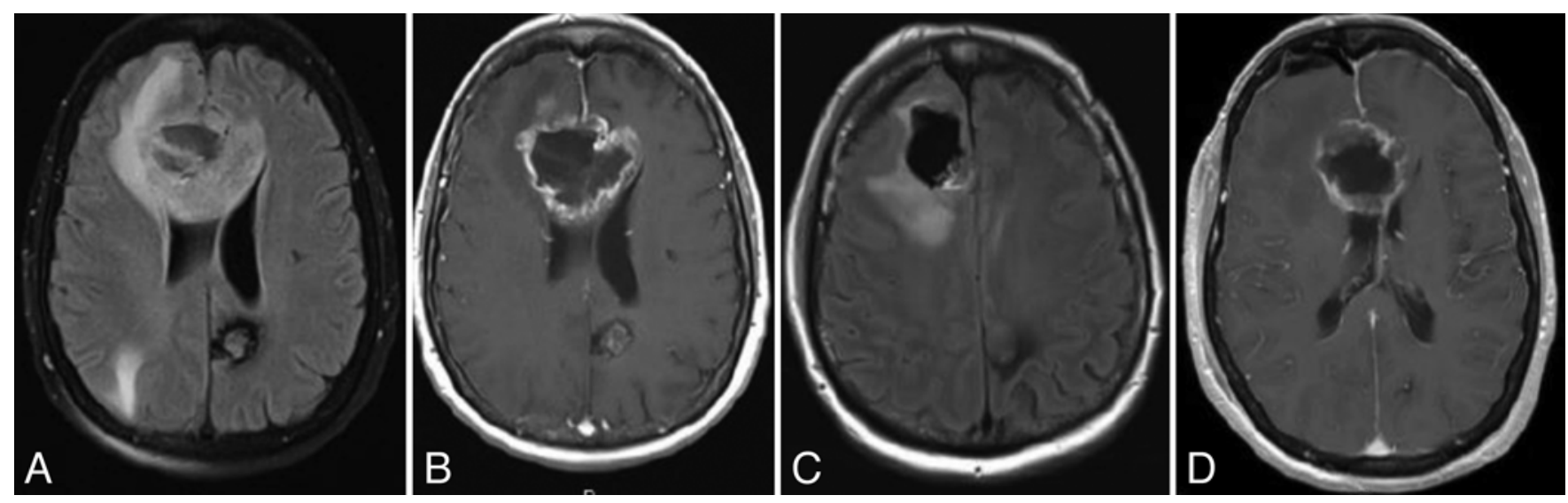

FIG. 2. Preoperative FLAIR sequence (A) and post-Gd T1-weighted sequence (B) demonstrate a large, ring-enhancing lesion in the corpus callosum with surrounding edema consistent with a butterfly GBM. A long-standing right occipital cavernoma is also visible. FLAIR sequence (C) and post-Gd T1-weighted sequence (D) obtained 48 hours postoperatively, showing decreased size of the cystic mass with a thin rim of enhancement and decreased edema. 

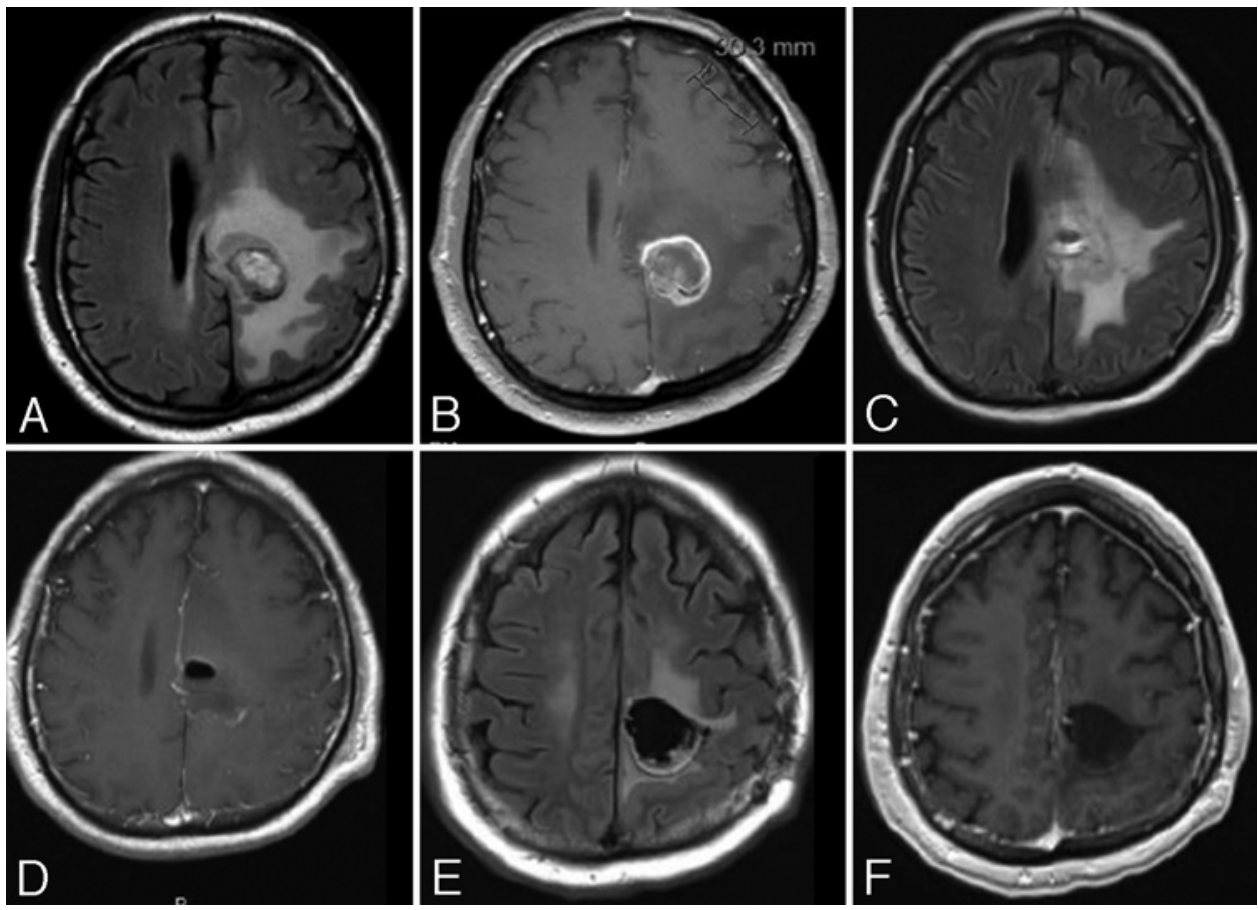

FIG. 3. Preoperative FLAIR sequence (A) and post-Gd T1-weighted sequence (B) demonstrate a large ring-enhancing left parietal lesion with significant surrounding edema in a patient with melanoma brain metastasis after WBRT, radiosurgery, and chemotherapy. This case proved to be recurrent melanoma brain metastasis with regions of radiation damage. FLAIR sequence (C) and post-Gd T1-weighted sequence (D) obtained 48 hours after surgery, showing decreased size of the cystic mass without evidence of enhancement and with markedly decreased edema. FLAIR sequence $(E)$ and post-Gd T1-weighted sequence (F) obtained more than 1 year postoperatively, demonstrating stabilization of lesion size without new enhancement and an additional decrease in edema.

noted above, their PFS and OS are comparable to those in most previously published series. The median PFS of 280 days (approximately 9.3 months) in our study compares favorably with the 4.6-month PFS of patients with tumors $\geq 10 \mathrm{~cm}^{3}$ treated with LITT in the multicenter study by Mohammadi et al. ${ }^{27}$ and is longer than the 2.9 months reported in another study of deep lesions. ${ }^{13}$ Similarly, the median OS of 482 days (approximately 16.1 months) in the present study is significantly longer than the 316 days in the first-in-man study of this technology, even though the median tumor volume in the latter study was significantly smaller $\left(6.8 \mathrm{~cm}^{3}\right) .{ }^{36}$

There have been several descriptions of minimally invasive tubular retractor systems used for transsulcal or parafascicular approaches to remove intracranial lesions. A frame-based system used in the late 1980s linked to a proprietary stereotactic system did not gain widespread acceptance and is no longer supported. ${ }^{19}$ More recent approaches have used smaller disposable devices compatible with various commercially available stereotactic systems. ${ }^{3,8}$ These have primarily been used for the resection of intraventricular and periventricular lesions and hematomas. ${ }^{3,8,31} \mathrm{~A}$ few papers have demonstrated some efficacy with the smaller disposable retractor systems in resecting intraparenchymal tumors, including a few gliomas, though their use does not appear to have become widespread. ${ }^{3,30}$ The senior author has tested the 2 devices currently available but does not use them routinely for malignant brain tumors given the importance of achieving an extensive re- section. However, for patients in the present study with tumors that would generally be considered unresectable, ${ }^{19,32}$ the goal was not to achieve a resection whose extent would be considered acceptable in a conventional study of surgery alone,${ }^{20}$ but rather to simply remove enough tumor tissue to compensate for the swelling expected after LITT for such large lesions while avoiding herniation or the need for emergent surgical intervention, as required in one of our previous cases and those described by others. ${ }^{6,13,15,28}$ However, after LITT, the tumor tissue appears to have a different, more gelatinous consistency and to be less vascular. These changes appeared to facilitate the use of a transsulcal tubular retractor system in 9 of the 10 cases presented here. Indeed, while our goal was simply to debulk dead tissue and thus to "create space" for the expected post-LITT swelling, this change in tumor consistency enabled rapid resection of extensive amounts of tumor (range $84 \%-100 \%$, mean 93\%) via a minimally invasive approach in a short time. The average time for the tumor resection (not including the craniotomy) was only about 20 minutes, and hemostasis was subjectively far more readily achieved than in DTA tumors not previously treated with LITT. Complications from the use of these retractor systems appear to be low for intraventricular and paraventricular approaches, but few groups have reported on the use of such retractors for the resection of intraparenchymal tumors. ${ }^{23-25}$

Two of our patients (20\%) suffered mild neurological injuries, one of which was transient. Both patients had 

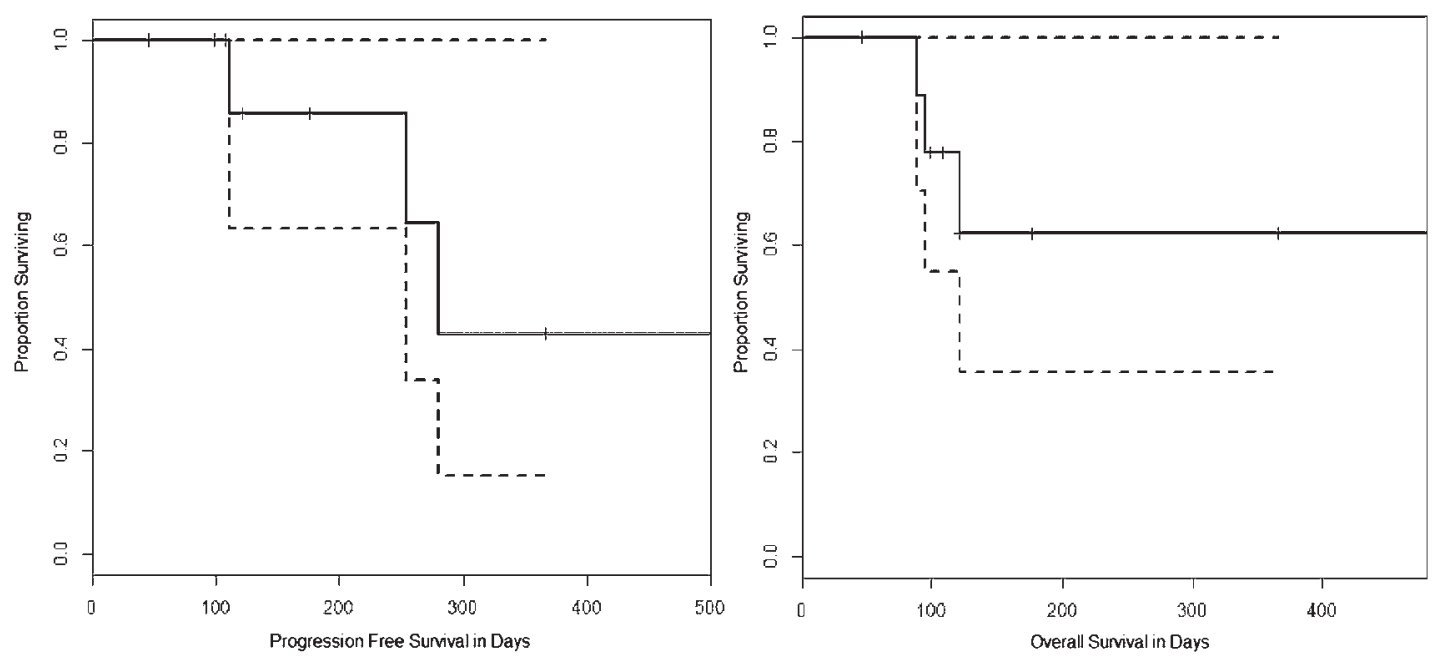

FIG. 4. Left: Progression-free survival. Right: Overall survival. Solid lines represent median PFS and OS, respectively; dashed lines reflect the $95 \%$ confidence intervals.

large lesions $\left(14.2-77.7 \mathrm{~cm}^{3}\right)$ in delicate regions of the brain (in and near the thalamus and corticospinal tracts) so the injury was not unexpected. Neurological deficits are the most common complications of LITT and have been reported in all studies of more than 10 patients, with an incidence ranging from $20 \%$ to $45 \% \cdot{ }^{13-15,26,27,36}$ Thus, the aggressive combinatorial approach described in our series of poor-prognosis DTA tumors is at the lower range of previously reported complications from LITT alone.

Postoperative communicating hydrocephalus also occurred in 1 patient $(10 \%)$ in our series. Postoperative hydrocephalus has been commonly observed in up to $15 \%$ of patients after ventricular opening, particularly in frontal lesions even after conventional approaches, as observed in this series. ${ }^{10,22}$ Hydrocephalus has also been reported after LITT, though infrequently. 28,33

Two patients in this series suffered postoperative infections. One patient (Case 1) had a true wound infection, as well as a seizure thought to be related to the infection. Several postoperative wound infections have been reported after LITT alone, ${ }^{26,27,36}$ including fatal meningitis. ${ }^{13,14}$ Infectious complications are probably related to comorbidities in this patient population including malignancy, immunosuppression and steroid use, poor wound healing due to radiation and chemotherapy, as well as age. Thus, while regrettable, the infection in our patient was not surprising. Note that this case was the first in which we had performed a craniotomy in the same procedure as the LITT. Subsequent analysis raised the possibility that the surgical field might have been contaminated after the sterile drape was incised for placement of the laser catheter, despite the use of a sterile technique with gowning and gloving, as well as the design of an iMRI unit with airflow consistent with operating room standards. Thus, after this first case, we performed a complete new prep and drape after LITT and before the craniotomy in the 9 subsequent patients, none of whom experienced infections of the surgical wound. The second infection (Case 4) occurred after one of the immobilizing pins lacerated the incision from an earlier procedure. This rare complication was probably related to the design of an early MR-compatible head clamp, which has since been replaced. This laceration was not bleeding at the end of the procedure and thus was not immediately noted. It represents a technical error related to the need for immobilization but is unrelated to the LITT or transsulcal approach. This complication is unique among the nearly 60 LITT cases and more than 200 craniotomies performed in our iMRI unit, and we think the risk of such a complication occurring again is remote. Both infections probably reflect the learning curve related to the early adoption of a new procedure, and both should be largely avoidable in the future by performing additional prep before the craniotomy post-LITT, which should also help avoid true infections. The adoption of more refined immobilization devices should also help to avoid scalp lacerations. There was only 1 complication (20\%) in the last 5 patients, which may further reflect additional experience in combining the 2 procedures.

\section{Conclusions}

In this series of 10 patients with poor-prognosis DTA tumors larger than $10 \mathrm{~cm}^{3}$ in volume, an aggressive approach combining LITT with immediate, minimally invasive transsulcal resection resulted in PFS and OS greater than that in previous series of LITT performed in patients with smaller lesions and lower risks. To our knowledge, such a combined procedure has not been reported. None of the patients required emergent decompressive procedures for intracranial swelling, as has been described in earlier studies of patients with large tumors. Neurological morbidity was at the lower range of previously reported rates, and there were no procedure-related deaths in our series. While morbidity was high relative to that following conventional surgery or LITT alone for smaller lesions, our combined approach provides the surgeon with a novel therapeutic option for ablating tumors in patients who would otherwise typically be treated with biopsy only. While technical challenges with this approach remain, they may simply represent the learning curve of this new 
and promising technology. By analogy, endoscopic neurosurgery was initially plagued by a high incidence of CSF leaks and hemorrhages, but after those challenges were addressed, this approach became mainstream for certain indications and is increasingly taught as a standard technique to residents and fellows. . $^{12,17,18}$ Similarly, LITT may continue to develop into a safer, more user-friendly technique. Further studies are needed.

\section{Acknowledgments}

This study was supported in part by the Peter D. Cristal Chair $\&$ the Kimble Family Foundation to A.E.S.

\section{References}

1. Agrawal A: Butterfly glioma of the corpus callosum. J Cancer Res Ther 5:43-45, 2009

2. Akiyama Y, Wanibuchi M, Mikami T, Horita Y, Komatsu K, Suzuki K, et al: Rigid endoscopic resection of deep-seated or intraventricular brain tumors. Neurol Res 37:278-282, 2015

3. Almenawer SA, Crevier L, Murty N, Kassam A, Reddy K: Minimal access to deep intracranial lesions using a serial dilatation technique: case-series and review of brain tubular retractor systems. Neurosurg Rev 36:321-330, 2013

4. Barnholtz-Sloan JS, Sloan AE, Schwartz AG: Chapter 25: Cancer of the brain and other central nervous system, in Gloeckler Ries LA, Young JL Jr, Keel GE, et al (eds): Cancer Survival Among Adults: US SEER Program, 1988-2001. Patient and Tumor Characteristics. Bethesda, MD: National Cancer Institute (http://seer.cancer.gov/archive/ publications/survival/seer_survival_mono_highres.pdf) [Accessed August 9, 2016]

5. Barnholtz-Sloan JS, Yu C, Sloan AE, Vengoechea J, Wang M, Dignam JJ, et al: A nomogram for individualized estimation of survival among patients with brain metastasis. Neuro Oncol 14:910-918, 2012

6. Carpentier A, McNichols RJ, Stafford RJ, Itzcovitz J, Guichard JP, Reizine D, et al: Real-time magnetic resonance-guided laser thermal therapy for focal metastatic brain tumors. Neurosurgery 63 (1 Suppl 1):ONS21-ONS29, 2008

7. Chen AM, Chang S, Pouliot J, Sneed PK, Prados MD, Lamborn KR, et al: Phase I trial of gross total resection, permanent iodine-125 brachytherapy, and hyperfractionated radiotherapy for newly diagnosed glioblastoma multiforme. Int J Radiat Oncol Biol Phys 69:825-830, 2007

8. Eliyas JK, Glynn R, Kulwin CG, Rovin R, Young R, Alzate $\mathrm{J}$, et al: Minimally invasive transsulcal resection of intraventricular and periventricular lesions through a tubular retractor system: multicentric experience and results. World Neurosurg 90:556-564, 2016

9. Engh JA, Lunsford LD, Amin DV, Ochalski PG, Fernandez-Miranda J, Prevedello DM, et al: Stereotactically guided endoscopic port surgery for intraventricular tumor and colloid cyst resection. Neurosurgery 67 (3 Suppl Operative):ons198-ons205, 2010

10. Fischer CM, Neidert MC, Péus D, Ulrich NH, Regli L, Krayenbühl N, et al: Hydrocephalus after resection and adjuvant radiochemotherapy in patients with glioblastoma. Clin Neurol Neurosurg 120:27-31, 2014

11. Gugger A, Barnhill RL, Seifert B, Dehler S, Moch H, Lugassy $\mathrm{C}$, et al: Cutaneous melanoma with brain metastasis: report of 193 patients with new observations. PLoS One 11:e0156115, 2016

12. Hadad G, Bassagasteguy L, Carrau RL, Mataza JC, Kassam A, Snyderman CH, et al: A novel reconstructive technique after endoscopic expanded endonasal approaches: vascular pedicle nasoseptal flap. Laryngoscope 116:1882-1886, 2006
13. Hawasli AH, Kim AH, Dunn GP, Tran DD, Leuthardt EC: Stereotactic laser ablation of high-grade gliomas. Neurosurg Focus 37(6):E1, 2014

14. Hawasli AH, Ray WZ, Murphy RKJ, Dacey RG, Leuthardt EC: Magnetic resonance imaging-guided focused laser interstitial thermal therapy for subinsular metastatic adenocarcinoma: technical case report. Neurosurgery (2 Suppl Operative) 70:332-338, 2012

15. Jethwa PR, Barrese JC, Gowda A, Shetty A, Danish SF: Magnetic resonance thermometry-guided laser-induced thermal therapy for intracranial neoplasms: initial experience. Neurosurgery 71 (1 Suppl Operative):133-145, 2012

16. Jethwa PR, Lee JH, Assina R, Keller IA, Danish SF: Treatment of a supratentorial primitive neuroectodermal tumor using magnetic resonance-guided laser-induced thermal therapy. J Neurosurg Pediatr 8:468-475, 2011

17. Kassam A, Horowitz M, Carrau R, Snyderman C, Welch W, Hirsch B, et al: Use of Tisseel fibrin sealant in neurosurgical procedures: incidence of cerebrospinal fluid leaks and cost-benefit analysis in a retrospective study. Neurosurgery 52:1102-1105, 2003

18. Kassam A, Snyderman CH, Carrau RL, Gardner P, Mintz A: Endoneurosurgical hemostasis techniques: lessons learned from 400 cases. Neurosurg Focus 19(1):E7, 2005

19. Kelly PJ, Kall BA, Goerss SJ: Computer-interactive stereotactic resection of deep-seated and centrally located intraaxial brain lesions. Appl Neurophysiol 50:107-113, 1987

20. Lacroix M, Abi-Said D, Fourney DR, Gokaslan ZL, Shi W, DeMonte F, et al: A multivariate analysis of 416 patients with glioblastoma multiforme: prognosis, extent of resection, and survival. J Neurosurg 95:190-198, 2001

21. Manjila S, Knudson KE, Johnson C, Sloan AE: Monteris AXiiiS stereotactic miniframe for intracranial biopsy: precision, feasibility, and ease of use. Neurosurgery [epub ahead of print], 2015

22. Marquardt G, Setzer M, Lang J, Seifert V: Delayed hydrocephalus after resection of supratentorial malignant gliomas. Acta Neurochir (Wien) 144:227-231, 2002

23. McLaughlin N, Ditzel Filho LFS, Prevedello DM, Kelly DF, Carrau RL, Kassam AB: Side-cutting aspiration device for endoscopic and microscopic tumor removal. J Neurol Surg B Skull Base 73:11-20, 2012

24. McLaughlin N, Kelly D, Prevedello D, Carrau R, Kassam A: Hemostasis management during completely endoscopic removal of a highly vascular intraparenchymal brain tumor: technique assessment. J Neurol Surg A Cent Eur Neurosurg 75:42-47, 2012

25. McLaughlin N, Prevedello DM, Engh J, Kelly DF, Kassam $\mathrm{AB}$ : Endoneurosurgical resection of intraventricular and intraparenchymal lesions using the port technique. World Neurosurg 79 (2 Suppl):S18.e1-S18.e8, 2013

26. Missios S, Bekelis K, Barnett GH: Renaissance of laser interstitial thermal ablation. Neurosurg Focus 38(3):E13, 2015

27. Mohammadi AM, Hawasli AH, Rodriguez A, Schroeder JL, Laxton AW, Elson P, et al: The role of laser interstitial thermal therapy in enhancing progression-free survival of difficult-to-access high-grade gliomas: a multicenter study. Cancer Med 3:971-979, 2014

28. Mohammadi AM, Schroeder JL: Laser interstitial thermal therapy in treatment of brain tumors - the NeuroBlate System. Expert Rev Med Devices 11:109-119, 2014

29. Norred SE, Johnson JA: Magnetic resonance-guided laser induced thermal therapy for glioblastoma multiforme: a review. BioMed Res Int 2014:761312, 2014

30. Raza SM, Recinos PF, Avendano J, Adams H, Jallo GI, Quinones-Hinojosa A: Minimally invasive trans-portal resection of deep intracranial lesions. Minim Invasive Neurosurg 54:5-11, 2011

31. Ritsma B, Kassam A, Dowlatshahi D, Nguyen T, Stotts G: 
Minimally invasive subcortical parafascicular transsulcal access for clot evacuation (Mi SPACE) for intracerebral hemorrhage. Case Rep Neurol Med 2014:102307, 2014

32. Sai Kiran NA, Thakar S, Dadlani R, Mohan D, Furtado SV, Ghosal N, et al: Surgical management of thalamic gliomas: case selection, technical considerations, and review of literature. Neurosurg Rev 36:383-393, 2013

33. Schroeder JL, Missios S, Barnett GH, Mohammadi AM: Laser interstitial thermal therapy as a novel treatment modality for brain tumors in the thalamus and basal ganglia. Photonics Lasers Med 3:151-158, 2013

34. Schwarzmaier HJ, Eickmeyer F, Fiedler VU, Ulrich F: Basic principles of laser induced interstitial thermotherapy in brain tumors. Med Laser Appl 17:147-158, 2002

35. Schwarzmaier HJ, Eickmeyer F, von Tempelhoff W, Fiedler VU, Niehoff H, Ulrich SD, et al: MR-guided laser-induced interstitial thermotherapy of recurrent glioblastoma multiforme: preliminary results in 16 patients. Eur J Radiol 59:208-215, 2006

36. Sloan AE, Ahluwalia MS, Valerio-Pascua J, Manjila S, Torchia MG, Jones SE, et al: Results of the NeuroBlate System first-in-humans Phase I clinical trial for recurrent glioblastoma: clinical article. J Neurosurg 118:1202-1219, 2013

37. Snyderman CH, Carrau RL, Prevedello DM, Gardner P, Kassam AB: Technologic innovations in neuroendoscopic surgery. Otolaryngol Clin North Am 42:883-890, 2009

38. Souhami L, Seiferheld W, Brachman D, Podgorsak EB, Werner-Wasik M, Lustig R, et al: Randomized comparison of stereotactic radiosurgery followed by conventional radiotherapy with carmustine to conventional radiotherapy with carmustine for patients with glioblastoma multiforme: report of Radiation Therapy Oncology Group 93-05 protocol. Int J Radiat Oncol Biol Phys 60:853-860, 2004
39. Stupp R, Mason WP, van den Bent MJ, Weller M, Fisher B, Taphoorn MJB, et al: Radiotherapy plus concomitant and adjuvant temozolomide for glioblastoma. N Engl J Med 352:987-996, 2005

\section{Disclosures}

Dr. Wright and Dr. Sloan have been paid consultants of Monteris Medical. Dr. Sloan is also a shareholder in Surgical Theatre and serves on its Medical Advisory Board.

\section{Author Contributions}

Conception and design: Sloan, J Wright, Chugh, C Wright, Alonso, Hdeib. Acquisition of data: all authors. Analysis and interpretation of data: all authors. Drafting the article: Sloan, J Wright, Chugh. Critically revising the article: Sloan, J Wright. Reviewed submitted version of manuscript: Sloan, J Wright, Chugh. Approved the final version of the manuscript on behalf of all authors: Sloan. Administrative/technical/material support: Sloan, J Wright.

\section{Supplemental Information \\ Videos \\ Video Abstract. https://vimeo.com/182386724.}

\section{Correspondence}

Andrew E. Sloan, Department of Neurological Surgery, University Hospitals Case Medical Center, Neurological Institute, and Case Comprehensive Cancer Center, 11100 Euclid Ave., Cleveland, OH 44106. email: andrew.sloan@uhhospitals.org. 